Article

\title{
The Preoperative Inflammatory Status Affects the Clinical Outcome in Cardiac Surgery
}

\author{
Donato D'Agostino ${ }^{1, *,+}$, Giangiuseppe Cappabianca ${ }^{2,+} \mathbb{D}$, Crescenzia Rotunno ${ }^{1}$, \\ Francesca Castellaneta ${ }^{3}$, Teresa Quagliara ${ }^{1}$, Alessandro Carrozzo ${ }^{1}$, Florinda Mastro ${ }^{1}$, \\ Ioannis Alexandros Charitos ${ }^{3}$, Cesare Beghi ${ }^{2}$ and Domenico Paparella ${ }^{1}$ (D) \\ 1 Department of Emergency and Organ Transplantations, Section of Cardiac Surgery, Consorziale Policlinico \\ University Hospital, Bari-University of Bari, 70124 Bari, Italy; crescenzia.rotunno@uniba.it (C.R.); \\ teresa.a.p.quagliara@gmail.com (T.Q.); alessandro_carrozzo@hotmail.it (A.C.); \\ florinda.gmastro@gmail.com (F.M.); domenico.paparella@uniba.it (D.P.) \\ 2 Department of Cardiac Surgery, "Circolo" Hospital, Insubria University, 21100 Varese, Italy; \\ giangiuseppe.cappabianca@asst-settelaghi.it (G.C.); cesare.beghi@uninsubria.it (C.B.) \\ 3 Department of Emergency/Urgency, Poisoning National Centre, "Riuniti” University Hospital, \\ 71100 Foggia, Italy; fra_c@live.com (F.C.); alexanestesia@hotmail.com (I.A.C.) \\ * Correspondence: d.dagostino@live.it \\ + These Authors have contributed equally to the work.
}

Received: 21 May 2019; Accepted: 28 September 2019; Published: 5 October 2019

check for updates

\begin{abstract}
Aims: There are many reasons for the increase in post-operative mortality and morbidity in patients undergoing surgery. In fact, an activated inflammatory state before cardiac surgery, can potentially worsen the patient's prognosis and the effects of this preoperative inflammatory state in the medium-term remains unknown. Methods: There were 470 consecutive patients who underwent cardiac surgery, and were divided in three groups according to the median values of preoperative $\mathrm{C}$-reactive protein (CRP) and fibrinogen (FBG): The first group was the low inflammatory status group (LIS) with 161 patients (CRP $<0.39 \mathrm{mg} / \mathrm{dL}$ and $\mathrm{FBG}<366 \mathrm{mg} / \mathrm{dL}$ ); the second was the medium inflammatory status group (MIS) with 150 patients (CRP $<0.39 \mathrm{mg} / \mathrm{dL}$ and FBG $\geq 366 \mathrm{mg} / \mathrm{dL}$ or CRP $\geq 0.39 \mathrm{mg} / \mathrm{dL}$ and $\mathrm{FBG}<366 \mathrm{mg} / \mathrm{dL}$ ); and the third was the high inflammatory status group (HIS) with 159 patients (CRP $\geq 0.39 \mathrm{mg} / \mathrm{dL}$ and $\mathrm{FBG} \geq 366 \mathrm{mg} / \mathrm{dL}$,). Results: The parameters to be considered for the patients before surgery were similar between the three groups except, however, for age, left ventricular ejection fraction (LVEF) and the presence of arterial hypertension. The operative mortality was not significantly different between the groups (LIS $=2.5 \%$, MIS $=6 \%$, HIS $=6.9 \%, p=0.16$ ) while mortality for sepsis was significantly different (LIS $=0 \%$, MIS $=1.3 \%$, HIS $=3.7 \%, p=0.03)$. The infections were more frequent in the HIS group $(p=0.0002)$. The HIS group resulted in an independent risk factor for infections (relative risk $(\mathrm{RR})=3.1$, confidence interval $(\mathrm{CI})=1.2-7.9, p=0.02$ ). During the 48-months follow-up, survival was lower for the HIS patients. This HIS group $(\mathrm{RR}=2.39, \mathrm{CI}=1.03-5.53, p=0.05)$ and $\operatorname{LVEF}(\mathrm{RR}=0.96, \mathrm{CI}=0.92-0.99, p=0.04)$ resulted in independent risk factors for mortality during the follow-up. Conclusions: The patients undergoing cardiac surgery with a preoperative highly activated inflammatory status are at a higher risk of post-operative infections. Furthermore, during the intermediate follow-up, the preoperative highly activated inflammatory status and LVEF resulted in independent risk factors for mortality.
\end{abstract}

Keywords: Inflammation; Inflammatory Status; C-Reactive Protein (CRP); Fibrinogen (FBG); Cardiac Surgery; Outcome; Clinical management; Infection risk; Sepsis; Cardio-Pulmonary Bypass (CBP) 


\section{Introduction}

Heart disease, including coronary artery disease and heart valve disease, is often associated with underlying and an unrecognised inflammatory status. The inflammatory system is an extremely complex, inter-correlated mechanism, in which numerous stimuli, mediators and effectors intervene simultaneously. Therefore, a number of measurable inflammatory markers could be found elevated in the patients with heart disease. C-reactive protein (CRP) and fibrinogen (FBG) seem to be the most significantly associated with cardiovascular events [1]. In fact, CRP and FBG consistently predict new coronary events in patients with unstable angina and myocardial infarction [2-5], and mitochondrial oxidative stress has also been evidenced to be an independent risk factor for restenosis after percutaneous coronary intervention (PCI) [5-8].

Degenerative aortic stenosis has been recognized as an inflammatory disease with several histological analogies with coronary atherosclerosis [9]. Many authors have demonstrated that the patients with calcific aortic stenosis have increased CRP plasma levels which decrease after native valve replacement $[10,11]$. The high plasma levels of CRP are also common in patients with chronic rheumatic valve disease [12] and significantly predict the outcome after percutaneous balloon mitral valve commissurotomy [13].

Moreover, the patients with heart failure, regardless of the etiology, have a chronic activation of the inflammatory system which is probably supported by the renin-angiotensin-aldosterone system $[12,14]$. These patients have elevated plasma levels of CRP [15]. A relationship between elevated CRP levels and mortality, New York Heart Association (NYHA) class and hospitalization was also observed $[15,16]$.

There are a few studies in the literature that analyse the effects of the preoperative inflammatory status on the prognosis of the patient undergoing cardiac surgery [17-19]. The authors observed that most of these show that the activated preoperative inflammatory state leads to a high incidence of infections after cardiac surgery. The effects of the pre-operative inflammatory status on the post cardiac surgery inflammatory reaction and on the mid-term outcome of the patients who have undergone surgical correction of their cardiac disease, remains to be demonstrated. The aim of this study is to evaluate the effects of the preoperative inflammatory status on a 48-month follow-up after cardiac surgery.

\section{Patients and Methods}

\subsection{Study Design}

This study is based on a retrospective analysis of prospectively collected clinical data. Over a period of three years (February 2012-February 2015), 1789 patients who underwent cardiac surgery at the authors' Institution were analysed. The patient candidates for cardiac operations were eligible in the study, except for the following exclusion criteria: emergency surgery, reoperations, the use of deep hypothermia presence of tumours or autoimmune disease and clinical signs of infections. This last condition was defined as the presence, at the time of hospital admission, of fever, or leukocytosis or of infective organ-related signs or symptoms (i.e.; productive cough, stranguria, sign of skin infections). Among the 578 patients in which preoperative CRP and fibrinogen values were available, 470 patients were suitable to be included in this study. The scattergram in Figure 1a shows the correlation between CRP and FBG baseline plasma levels (coefficient 0.57, $p<0.0001$ ). With the goal of comparing the outcome of the patients with different preoperative activation of the inflammatory system, the median values of CRP $(0.39 \mathrm{mg} / \mathrm{dL})$ and FBG $(366 \mathrm{mg} / \mathrm{dL})$ were employed to divide the population in three groups: The low inflammatory status group (LIS), composed of 161 patients with CRP $<0.39 \mathrm{mg} / \mathrm{dL}$ and FBG $<366 \mathrm{mg} / \mathrm{dL}$; the medium inflammatory status group (MIS) composed of 150 patients with CRP $<0.39 \mathrm{mg} / \mathrm{dL}$ and FBG $\geq 366 \mathrm{mg} / \mathrm{dL}$ or CRP $\geq 0.39 \mathrm{mg} / \mathrm{dL}$ and FBG $<366 \mathrm{mg} / \mathrm{dL}$; the high inflammatory status group (HIS), composed of 159 patients with CRP $\geq 0.39 \mathrm{mg} / \mathrm{dL}$ and FBG $\geq 366 \mathrm{mg} / \mathrm{dL}$. The clinical data were prospectively collected in the authors' institutional electronic database by trained personnel. 
The end points of this study related to the preoperative inflammatory status were twofold: First, to evaluate the effect on medium-term survival and their discharge from hospitalization for cardiac causes after cardiac surgery; second, to verify the effect on mortality and hospital morbidity.

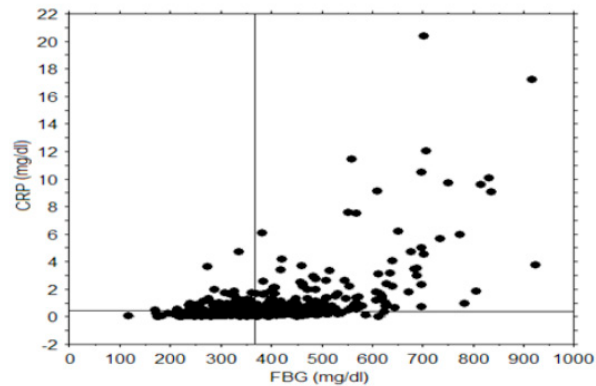

(a)

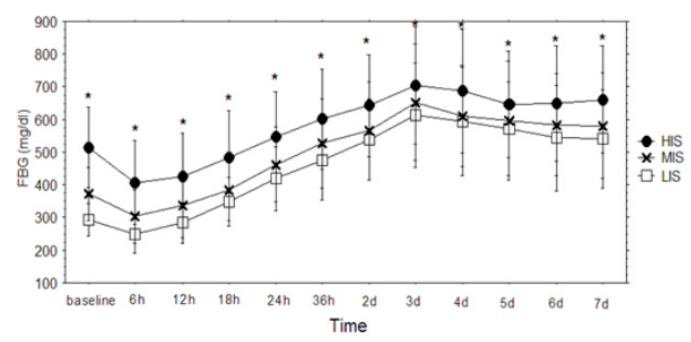

(c)

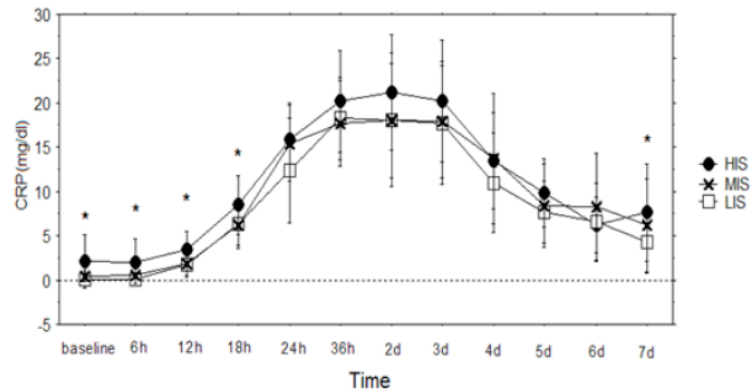

(b)

Figure 1. (a) A scattergram of preoperative C-reactive protein (CRP) and Fibrinogen (FBG) plasma levels of 470 patients who had undergone cardiac surgery. The two lines which cross the box represent the median values of CRP $(0.39 \mathrm{mg} / \mathrm{dL})$ and FBG $(366 \mathrm{mg} / \mathrm{dL})$. (b) Perioperative values of C-reactive protein (CRP) in the low inflammatory group (LIS), medium inflammatory group (MIS) and high inflammatory group (HIS). The asterisks mark differences with $p \leq 0.05$. (c) Perioperative values of fibrinogen (FBG) in the low inflammatory group (LIS), medium inflammatory group (MIS) and high inflammatory group (HIS). The asterisks mark differences with $p \leq 0.05$.

\subsection{Operation Techniques}

The anesthetic management of the patients was with general anesthesia using lorazepam as a premedication and intravenous induction for intubation was done with fentanyl, midazolam and thiopental sodium. During the cardiac operation, general anesthesia was maintained by intravenous continuous controlled infusion of propofol. Median sternotomy was the surgical approach. Cardiac arrest was induced and maintained with cold-blooded anterograde cardioplegia and cardio-pulmonary bypass (CPB) was performed at moderate hypothermia $\left(34^{\circ} \mathrm{C}\right)$. Heparin $(300 \mathrm{U} / \mathrm{kg})$ was administered and intra-operative heparin monitoring was performed using the standard activated clotting time (ACT, Hemochron 8). The additional heparin bolus ( $5000 \mathrm{U}$ ) were given if the ACT value was below 400 seconds. Protamine was administered to reverse heparin $(1 \mathrm{mg}$ of protamine per milligram of total heparin given before and during $\mathrm{CPB}$ ). The off pump coronary revascularizations were carried out with the use of Lima stitch and intracoronary shunts in all patients. Anesthesia and anticoagulation management was not different to the one used for the patients who had undergone CPB. In all the patients who had undergone valve replacement, a mechanical bi-leaflet prosthesis was implanted.

\subsection{Definitions}

Unstable angina was defined as on-going refractory angina that requires the use of intravenous nitrate therapy for control. The left ventricular ejection fraction (LVEF) was obtained in all the patients by left ventriculogram. Post-operative mortality was defined as the death, regardless of the cause in 
the same hospital admission of the patients after surgery. Cardiac death has been defined as a death due solely to heart damage, including sudden death as an unexpected death due to cardiac causes occurring immediately after the onset of symptoms (within an hour) or even without the onset of symptoms. The post-operative presence of low cardiac output syndrome (LOS) was defined as the reduction of cardiac output and the application in support of cardiac function and cardiac output of inotropic and post-load reducing agents or through mechanical circulatory support with an intra-aortic balloon pump for more than 30 minutes in intensive care unit (ICU). The goal was to maintain systolic blood pressure (SP) $>90 \mathrm{~mm} \mathrm{Hg}$, the mean arterial pressure (MAP) $>60 \mathrm{~mm} \mathrm{Hg}$ ) or the cardiac index (CI) $>2.2 \mathrm{~L} / \mathrm{min} / \mathrm{m}^{2}$, despite adequate volume resuscitation. According to anesthesiologists' protocols, extubation criteria were: hemodynamic stability, the absence of surgical bleeding, fully re-warming, awakeness, optimal blood gases with $\mathrm{FIO}_{2} \leq 0.3$ and without the need for mechanical assistance. Sepsis was defined according to its current classification by at least two of the following clinical criteria: body temperature $<36{ }^{\circ} \mathrm{C}$ or $>38^{\circ} \mathrm{C}$; heart rate $>90$ beats/minute; respiratory rate $>20$ breaths/minute; $\mathrm{PCO}_{2}<32 \mathrm{~mm} \mathrm{Hg}$; white blood cells $>12000$ or $<4000 / \mathrm{L}$ [20].

\subsection{Biochemistry}

The blood samples were collected pre-operatively on the morning of the operation and at 1 , $6,12,24,36$ hours after the end of the operations and every day from the second to the seventh post-operative day. The high-sensitivity C-reactive protein (hsCRP) measurements were detected based on the immunoassay technique through Flex ${ }^{\circledR}$ reagent cartridge, Dade Behring Inc.; Newark, DE, and FBG was measured with the Clauss clotting time method (Biopool Fibrinogen Assay Kit, Biopool International, Ventura, CA, USA).

\subsection{Follow-up}

After being discharged from the hospital, the patients were evaluated periodically at the follow-up by going to the authors' Institute or by contacting their general practitioner by phone call or by the medical staff. The follow-up was $94.8 \%$ complete (423/446). The maximum and mean follow-up were 48.6 and $19.6 \pm 11$ months.

\subsection{Statistical Analyses}

The continuous variables were presented as the mean \pm standard deviation and were compared with an analysis of variance (ANOVA). The categorical variables were presented as absolute numbers and percentages and were compared using the $\chi^{2}$ test. The repeated ANOVA measures were employed to evaluate the differences in postoperative plasma levels of CRP and FBG between the three groups. The differences between the study groups were considered statistically significant when $p \leq 0.05$. The outcome variables were significantly different for the univariate analysis, and underwent multivariate analysis by logistic regression, matching the preoperative inflammatory status versus the pre and intra-operative variables which had results different from the comparison of the three groups. For the outcome, the variables were independently influenced by the inflammatory status. The receiver operating characteristic curves (ROC curves) were used to establish the best cut-off of CRP and FBG. The Kaplan and Mayer curves were employed to evaluate survival and freedom from hospitalization for cardiac events. The curves of the three groups were compared by the log rank test. If the log rank test was significant, the Cox model was applied to verify the independent effect of the group on the outcomes, compared to the other significantly different variables. The statistical analyses were performed using the Stat-View Statistical Software Package (SAS Institute Inc. Cary, NC, USA) and Number Cruncher Statistical System (NCSS, Kaysville, Utah, USA). 


\section{Results}

\subsection{Laboratory Results}

The repeated ANOVA measures showed that the patients with preoperative highly activated inflammatory status have significantly higher plasma levels of CRP during the postoperative period $(\mathrm{f}$-ratio $=4.28, p=0.01)$. CRP mean the preoperative values (Figure $1 \mathrm{~b}$ ) were: $0.18 \pm 0.09 \mathrm{mg} / \mathrm{dL}$ for the LIS group, $0.54 \pm 0.59 \mathrm{mg} / \mathrm{dL}$ for the MIS group and $2.2 \pm 3.02$ for the HIS group $(p<0.0001)$. The CRP postoperative peak values were observed 48 hours after the operation $(\mathrm{LIS}=18.1 \pm 6.4 \mathrm{mg} / \mathrm{dL}$, MIS $=18.1 \pm 7.5 \mathrm{mg} / \mathrm{dL}$, HIS $21.2 \pm 6.4 \mathrm{mg} / \mathrm{dL}, p=0.11) . \quad$ In the seventh post-operative day, the patients of the HIS group still had significantly higher CRP plasma levels (LIS $=4.3 \pm 3.4 \mathrm{mg} / \mathrm{dL}$, MIS $=6.2 \pm 5.2 \mathrm{mg} / \mathrm{dL}$ HIS $=7.7 \pm 5.4 \mathrm{mg} / \mathrm{dL}, p=0.01)$. The fibrinogen mean preoperative values (Figure 1c) were: $292.4 \pm 49.3 \mathrm{mg} / \mathrm{dL}$ in the LIS group, $371.1 \pm 80.6 \mathrm{mg} / \mathrm{dL}$ in the MIS group and $513.3 \pm 123.2 \mathrm{mg} / \mathrm{dL}$ in the HIS group $(p<0.0001)$. Postoperatively, after an initial drop probably caused by hemodilution, the fibrinogen peak values were observed in the third post-operative day (LIS = $612 \pm 159.7 \mathrm{mg} / \mathrm{dL}, \mathrm{MIS}=650.3 \pm 177.8 \mathrm{mg} / \mathrm{dL}, \mathrm{HIS}=702.2 \pm 178.4 \mathrm{mg} / \mathrm{dL}$ $p=0.0002)$. In the seventh post-operative day, the HIS group still had significantly higher FBG plasma levels (LIS = $538.6 \pm 150.2 \mathrm{mg} / \mathrm{dL}$, MIS = $579.6 \pm 160.1 \mathrm{mg} / \mathrm{dL}$, HIS $659 \pm 164.1 \mathrm{mg} / \mathrm{dL} p<0.0001$ ). The repeated ANOVA measures confirmed that the patients with a preoperative inflammatory status have significantly higher fibrinogen plasma levels in the postoperative period (f-ratio $=2.69, p<0.0001$ ).

\subsection{Clinical Results}

The preoperative clinical status was comparable among the groups except for age, preoperative left ventricular ejection fraction and the incidence of hypertension (Table 1). The preoperative assumption of statins was similar in the three groups. The types of surgical procedures performed in the three groups were equally distributed but the CPB time was longer in the patients of the HIS group (Table 2). The off-pump procedures were also similarly distributed in the three groups. Overall, operative mortality was $5.1 \%(24 / 470), 2.5 \%$ in the LIS group, $6 \%$ in the MIS $6 \%$ and $6.9 \%$ in the HIS group without a statistically significant difference $(p=0.16)$. The causes of death are listed in Table 3 . The patients in the HIS group had a significantly higher incidence of death caused by sepsis. The univariate analysis of post-operative morbidity is shown in Table 2: A preoperative highly activated inflammatory status is associated with a significantly higher incidence of mechanical ventilation $>24 \mathrm{~h}$, the need of dialysis/ultrafiltration, sepsis, sternal wound and overall infections. In the multivariate analysis, the preoperative high inflammatory status (HIS) was the only independent risk factor for sternal wound infections (risk ratio $(\mathrm{RR})=3.5, \mathrm{CI}=1.04-11.8, p=0.04)$ and overall infections $(\mathrm{RR}=3.1, \mathrm{CI}=1.2-7.9$, $p=0.02)$. The ROC curves evidenced that the best cut-off values to predict sternal wound infections were $0.66 \mathrm{mg} / \mathrm{dL}$ for CRP (sensitivity $68.7 \%$, specificity $69.8 \%$, area under the curve (AUC) $=64.7 \%$ ) and $367.9 \mathrm{mg} / \mathrm{dL}$ for FBG (sensitivity 75\%, specificity $52.5 \%$, AUC $=64.6 \%$ ). The best cut-off values to predict overall infections were $0.66 \mathrm{mg} / \mathrm{dL}$ for CRP (sensitivity $62 \%$, specificity $70.7 \%$, (AUC) $=64.6 \%$ ) and $367.9 \mathrm{mg} / \mathrm{dL}$ for FBG (sensitivity $72 \%$, specificity $53.3 \%$, AUC $=64.3 \%$ ). 
Table 1. Preoperative characteristics.

\begin{tabular}{ccccc}
\hline & LIS & MIS & HIS & $p$ \\
\hline Patients & 161 & 150 & 159 & \\
Age (years) & $63.1 \pm 10.2$ & $65.5 \pm 9.6$ & $66.2 \pm 8.8$ & 0.01 \\
Male & $126(78.3 \%)$ & $104(69.3 \%)$ & $116(73 \%)$ & 0.19 \\
BSA (m $\left.{ }^{2}\right)$ & $1.79 \pm 0.18$ & $1.76 \pm 0.16$ & $1.78 \pm 0.16$ & 0.46 \\
Unstable Angina & $19(11.8 \%)$ & $23(15.3 \%)$ & $25(15.7 \%)$ & 0.54 \\
MI $<$ 21 days & $31(19.3 \%)$ & $29(19.3 \%)$ & $41(25.8 \%)$ & 0.26 \\
Calcific Aortic Stenosis & $12(7.4 \%)$ & $15(10 \%)$ & $9(5.6 \%)$ & 0.35 \\
Rheumatic valvular disease & $8(4.9 \%)$ & $7(4.7 \%)$ & $4(2.5 \%)$ & 0.48 \\
LVEF (\%) & $49.2 \pm 8.8$ & $49.9 \pm 9.9$ & $46.8 \pm 10.6$ & 0.02 \\
Hypertension & $88(54.7 \%)$ & $94(62.7 \%)$ & $115(72.3 \%)$ & 0.005 \\
Diabetes & $49(30.4 \%)$ & $41(27.3 \%)$ & $50(31.4 \%)$ & 0.71 \\
Hypercholesterolemia & $75(46.6 \%)$ & $83(55.3 \%)$ & $89(56 \%)$ & 0.17 \\
Statins therapy & $55(34.2 \%)$ & $61(40.6)$ & $67(42.1)$ & 0.29 \\
Smoking history & $37(23 \%)$ & $34(22.7 \%)$ & $52(32.7 \%)$ & 0.07 \\
COPD & $39(24.2 \%)$ & $37(24.7 \%)$ & $46(28.9 \%)$ & 0.57 \\
C.A. Stenosis $>60 \%$ & $7(4.3 \%)$ & $9(6 \%)$ & $13(8.2 \%)$ & 0.36 \\
CVA < 21 days & $1(0.6 \%)$ & $1(0.7 \%)$ & $4(2.5 \%)$ & 0.23 \\
Preop. cTnI (ng/mL) & $0.11 \pm 0.42$ & $0.21 \pm 1.2$ & $0.40 \pm 1.43$ & 0.15 \\
\hline
\end{tabular}

$\mathrm{BSA}=$ body surface area; $\mathrm{MI}=$ myocardial infarction; $\mathrm{LVEF}=$ left ventricular ejection fraction; $\mathrm{COPD}=$ chronic obstructive pulmonary disease; C.A. = carotid artery; $\mathrm{CVA}=$ cerebrovascular accident; Preop $\mathrm{cTnI}=$ preoperative cardiac Troponin I.

Table 2. Operative variables.

\begin{tabular}{ccccc}
\hline & LIS & MIS & HIS & $p$ \\
\hline Patients & 161 & 150 & 159 & \\
CABG & $79(49.1 \%)$ & $72(48 \%)$ & $81(50.9 \%)$ & 0.87 \\
OPCAB & $38(23.6 \%)$ & $30(20 \%)$ & $44(27.7 \%)$ & 0.28 \\
Aortic Root surgery & $3(1.9 \%)$ & $3(2 \%)$ & $6(3.8 \%)$ & 0.48 \\
AVR & $12(7.5 \%)$ & $17(11.3 \%)$ & $9(5.7 \%)$ & 0.17 \\
Mitral replacement/repair & $7(4.3 \%)$ & $14(9.3 \%)$ & $10(6.3 \%)$ & 0.2 \\
Combined procedures & $16(9.9 \%)$ & $13(8.7 \%)$ & $8(5 \%)$ & 0.24 \\
Other procedures & $6(3.7 \%)$ & $1(0.7 \%)$ & $1(0.6 \%)$ & 0.06 \\
CPB duration (min) & $105 \pm 28$ & $114 \pm 44$ & $120 \pm 34$ & 0.006 \\
X-Clamp duration (min) & $58 \pm 22$ & $63 \pm 23$ & $62 \pm 23$ & 0.3 \\
\hline
\end{tabular}

$\mathrm{OPCAB}=$ off-pump coronary artery bypass; $\mathrm{AVR}=$ aortic valve replacement; $\mathrm{CPB}=$ cardiopulmonary bypass. 
Table 3. Post-operative mortality (M 1) and morbidity (M 2), related to pre-operative inflammatory status.

\begin{tabular}{|c|c|c|c|c|}
\hline & LIS & MIS & HIS & $p$ \\
\hline \multicolumn{5}{|l|}{ M 1} \\
\hline Patients & 161 & 150 & 159 & \\
\hline Operative Mortality & $4(2.5 \%)$ & $9(6 \%)$ & $11(6.9 \%)$ & 0.16 \\
\hline \multicolumn{5}{|l|}{ Causes of death } \\
\hline Cardiac death & $4(2.5 \%)$ & $5(3.3 \%)$ & $3(1.8 \%)$ & 0.72 \\
\hline Sepsis & 0 & $2(1.3 \%)$ & $6(3.7 \%)$ & 0.03 \\
\hline Stroke & 0 & $1(0.7 \%)$ & $1(0.6 \%)$ & 0.59 \\
\hline Bleeding & 0 & $1(0.7 \%)$ & $1(0.6 \%)$ & 0.59 \\
\hline \multicolumn{5}{|l|}{ M 2} \\
\hline ICU stay $(\mathrm{h})$ & $46.9 \pm 28.5$ & $62.1 \pm 78.9$ & $65.6 \pm 101.2$ & 0.07 \\
\hline Overall stay (days) & $8.1 \pm 4.9$ & $9.9 \pm 8.2$ & $9.7 \pm 71.8$ & 0.06 \\
\hline Mechanical ventilation $>24 \mathrm{~h}$ & $13(8.1 \%)$ & $26(17.3 \%)$ & $32(20.1 \%)$ & 0.007 \\
\hline Reintubation & $3(1.9 \%)$ & $8(5.3 \%)$ & $8(5 \%)$ & 0.22 \\
\hline LOS & $19(11.8 \%)$ & $26(17.3 \%)$ & $26(16.4 \%)$ & 0.34 \\
\hline IABP & $4(2.5 \%)$ & $9(6 \%)$ & $7(4.4 \%)$ & 0.31 \\
\hline cTnI peak $(\mathrm{ng} / \mathrm{mL})$ & $15.9 \pm 35.2$ & $15.5 \pm 19.6$ & $19.5 \pm 49.5$ & 0.56 \\
\hline Dialysis/Ultrafiltration & 0 & $4(2.7 \%)$ & $7(4.4 \%)$ & 0.03 \\
\hline AF onset & $43(26.7 \%)$ & $41(27.3 \%)$ & $41(25.8 \%)$ & 0.95 \\
\hline CVA & 0 & $4(2.7 \%)$ & $4(2.5 \%)$ & 0.11 \\
\hline Sepsis & 0 & $5(3.3 \%)$ & $6(3.8 \%)$ & 0.05 \\
\hline Sternal wound infection & $5(3.1 \%)$ & $7(4.7 \%)$ & $20(12.6 \%)$ & 0.002 \\
\hline Overall infections & $9(5.6 \%)$ & $11(7.3 \%)$ & $30(18.9 \%)$ & 0.0002 \\
\hline Blood loss (ml) & $840.4 \pm 432.4$ & $745.4 \pm 406.7$ & $776.2 \pm 500.1$ & 0.17 \\
\hline Reopening for bleeding & $2(1.2 \%)$ & $1(0.7 \%)$ & $3(1.9 \%)$ & 0.63 \\
\hline Blood Units transfusion (mean value) & $1.5 \pm 2.2$ & $1.9 \pm 2.7$ & $2.1 \pm 4.4$ & 0.18 \\
\hline FFP Units transfusion (mean value) & $0.3 \pm 1.4$ & $0.3 \pm 1.1$ & $0.5 \pm 2.4$ & 0.53 \\
\hline Platelet Units transfusion (mean value) & $0.2 \pm 0.9$ & $0.2 \pm 1.1$ & $0.2 \pm 1$ & 0.97 \\
\hline
\end{tabular}

ICU = Intensive Care Unit; LOS = low cardiac output syndrome; IABP = intra-aortic balloon pump; cTnI = cardiac Troponin I peak; $\mathrm{AF}=$ atrial fibrillation; $\mathrm{CVA}=$ cerebro-vascular accident; $\mathrm{FFP}=$ fresh frozen plasma.

\subsection{Follow-up}

At forty-eight months survival (Figure 2a) among the three groups of the patients, it was demonstrated that the best survival was that of the LIS $(91.9 \pm 3.1 \%)$ compared to the MIS $(84.3 \pm 4.8$, $p=0.13)$ and the HIS $(85.7 \pm 3.0 \%, p=0.01)$. Furthermore, the Cox regression revealed for the HIS group, the risk ratio for infections $(\mathrm{RR}=2.39, \mathrm{CI}=1.03-5.53, p=0.05)$ and the $\operatorname{LVEF}(\mathrm{RR}=0.96$, $\mathrm{CI}=0.92-0.99, p=0.04)$ were independent risk factors for mortality during 48-months follow-up. The ROC curves for survival evidenced that the best CRP cut-off value was $0.5 \mathrm{mg} / \mathrm{dl}$ (sensitivity $59.1 \%$, specificity $59.6 \%$, AUC $=60.2 \%$ ), the best FBG cut-off value was $321 \mathrm{mg} / \mathrm{dL}$ (sensitivity $=90.9 \%$, specificity $=34.8 \%$ AUC $=63 \%$ ), and the best cut-off LVEF was $42 \%$ (sensitivity $47.3 \%$, specificity $78.4 \%$, AUC $=61.3 \%$ ). Furthermore, in the subgroup of the patients who had undergone coronary artery bypass grafting (CABG) (Figure $2 b$ ), survival was better for the LIS group $(91.5 \pm 3.7 \%$ ) compared to the MIS group $(85.4 \pm 5.4 \%, p=0.16)$ and the HIS group patients $(87.7 \pm 3.1 \%, p=0.06)$. In the subgroup of the patients who had undergone cardiac surgery other than CABG (Figure 2c), survival was $93.8 \pm 4.3 \%$ for the LIS group, $82.9 \pm 9.1 \%$ for the MIS group ( $p=0.69$ compared to LIS group) and $75.6 \pm 8.7 \%$ for the HIS group ( $p=0.06$ compared to LIS group). The freedom from hospitalization for cardiac events (Figure 3 ) was higher for the LIS group $(92.2 \pm 2.9 \%)$ compared to the MIS group $(88.6 \pm 3.4 \%, p=0.38)$ and the HIS group patients $(72.2 \pm 8.4 \%, p=0.07)$. 


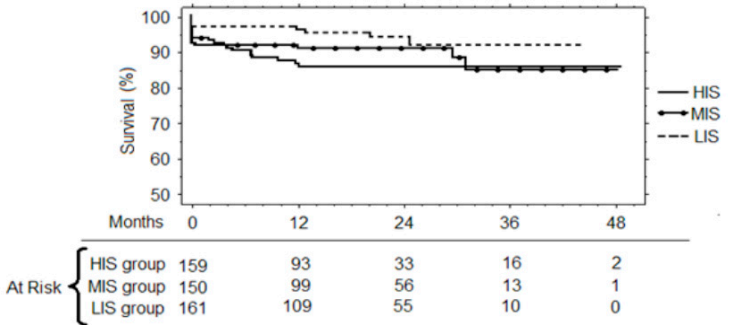

(a)

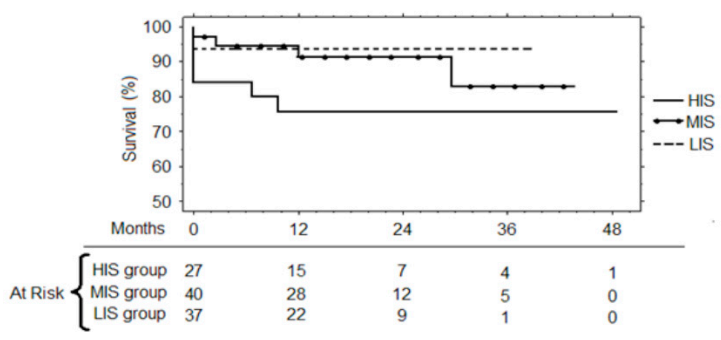

(c)

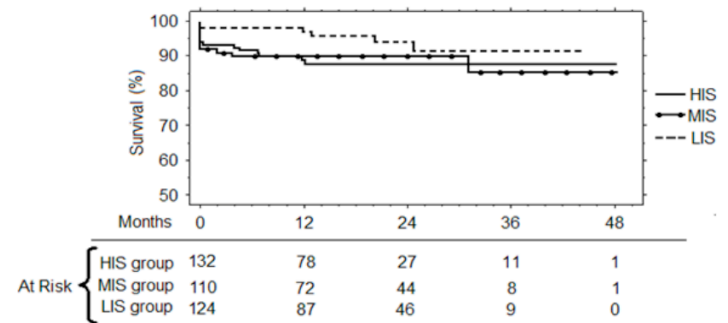

(b)

Figure 2. (a) The 48-months survival for patients of the LIS, MIS and HIS group. (b) Subgroup of patients undergone coronary artery bypass grafting (CABG): The 48-months survival for patients of the LIS, MIS and HIS group. (c) The subgroup of patients undergone cardiac surgery other than CABG: The 48-months survival for patients of the LIS, MIS and HIS group.

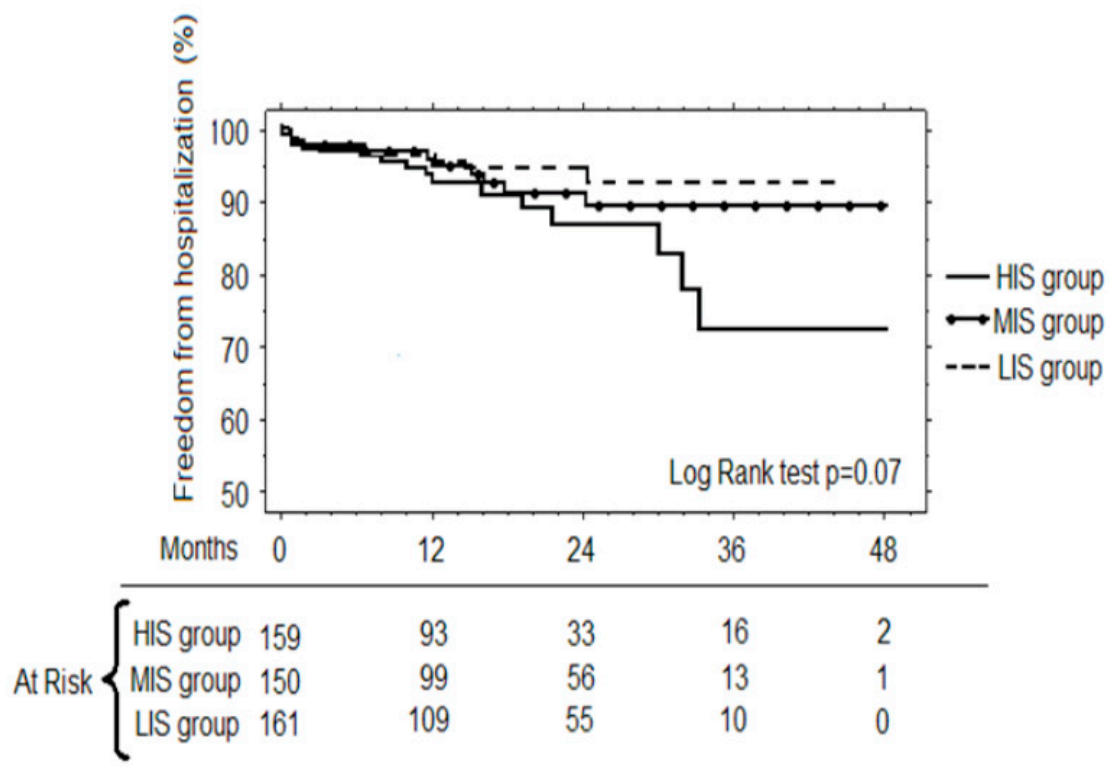

Figure 3. The 48-months freedom from hospitalization for cardiac events for patients of the LIS, MIS and HIS group.

\section{Discussion}

CRP is an acute-phase protein mainly produced by the liver in response to interleukin 6 (IL-6). It is a pentameric protein composed of five identical units that are implicated in the synthesis of interleukin 1 and tumour necrosis factor, in the modulation of macrophage activity and in the activation of the complement system [21]. FBG is the substrate for the fibrin production, participates in platelet aggregation and acts as acute phase protein, increasing during inflammatory responses. Combining CRP and FBG values, three different preoperative inflammatory status levels were defined in this study. It is believed that the association of 2 reliable markers allowed the identification of a group of patients with an extremely activated preoperative inflammatory state (HIS group). This study would not have had 
the same selection by using a single inflammatory marker. The degree of the preoperative inflammatory status in the patients undergoing cardiac surgery can be influenced by several factors. The development of atherosclerotic plaques depends considerably on the inflammatory cascade and therefore, this complication appears to be the inflammatory response to endothelium lesions due to the various causes of risk such as hypertension, smoking, diabetes and hypercholesterolemia [1]. In this study, the patients with a high inflammatory status had an elevated incidence of hypertension, while smoking history, diabetes mellitus and hypercholesterolemia were similarly distributed. The patients of the HIS group had a higher incidence of unstable angina and recent myocardial infarction, although the difference was not statistically significant. Other reports evidenced significantly higher levels of CRP and IL-6 in the patients with unstable angina and myocardial infarction, supporting the connection between acute coronary syndromes and inflammatory status $[1,2,4]$. In this study, the patients with a highly activated preoperative inflammatory status (HIS) had a significantly lower LVEF, and a correlation between left ventricular dysfunction and CRP has already been reported [14-16]. The patients with calcific aortic stenosis and chronic rheumatic valve disease were similarly distributed in the three groups. This finding is in contrast with other studies [9-11] that reported high preoperative CRP plasma levels in these two kinds of diseases.

Following surgery, the CRP plasma levels were observed to increase, reaching the peak in the second post-operative day. This finding is consistent with those reported by Gaudino and co-workers [22]. Before the discharge home, the HIS group patients had still higher levels of CRP. Compared to CRP, FBG remains higher until discharge, acting as a late acute phase protein. This study shows that the preoperative inflammatory status significantly influences the magnitude of the inflammatory reaction provoked by the operation. Therefore, the preoperative inflammatory status could be considered a risk factor for post-operative inflammatory reaction, magnifying the effects of the intraoperative inflammatory stressors (cardiopulmonary bypass, ischemia, ischemia-reperfusion injury, endotoxin release and surgical trauma). The development of postoperative complications such as myocardial dysfunction, respiratory failure, renal and neurologic dysfunction, bleeding, altered liver function, and ultimately, multiple organ failure may relate to the degree of the postoperative inflammatory reaction. The possibility to predict the magnitude of this reaction may facilitate the adoption of different pharmacological or technical strategies (administration of glucocorticoids, protease inhibitors, antioxidants, use of coated circuits, pulsatile flow during $\mathrm{CPB}$, the use of techniques aimed at reducing oxidative stress, etc.), able to minimize the post-operative inflammatory reaction in patients at risk [23-36].

In this study, the patients with a preoperative highly activated inflammatory status (HIS) had a higher, but not statistically significant hospital mortality. The data in this study confirm that an increased preoperative inflammatory state facilitates postoperative infective complications. Biancari and colleagues [17] reported that approximately 764 patients who had undergone CABG, preoperative PCR $>1 \mathrm{mg} / \mathrm{dL}$ was recognized as an independent risk factor for operative mortality (RR 6.97, CI = 1.44-33.42, $p=0.01)$. In this study, although the HIS group patients had worse preoperative clinical conditions, an increased rate of operative mortality for cardiac causes was not observed, while the mortality for sepsis was significantly influenced by the preoperative inflammatory status. The multivariate analysis showed that the preoperative inflammatory status was the only independent risk factor for post-operative infections. A previous report by Boeken [18] regarding 100 patients undergone cardiac surgery with cardiopulmonary bypass evidenced that patients with preoperative CRP $>0.5 \mathrm{mg} / \mathrm{dL} \mathrm{had}$ higher incidence of septic complications, need of inotropic support and a significantly longer duration of mechanical ventilation and intensive care unit (ICU) stay. Accordingly, Fransen [19] evidenced that a $\mathrm{CRP}>0.8 \mathrm{mg} / \mathrm{dL}$ was an independent risk factor for post-operative infections $(\mathrm{RR}=2.7, \mathrm{CI}=1.7-4.3$, $p<0.0001$ [22]. The two hypotheses of why the higher rate of postoperative infectious complications occur in patients with a high preoperative inflammatory status can be observed. The first is based on the observation that bacterial growth increases in the presence of high concentrations of pro-inflammatory mediators with related mortality to the degree of the spread and duration of the inflammatory response 
of the host $[37,38]$. The second, as demonstrated by Meduri and colleagues, is that in patients with an acute respiratory distress syndrome, the development of a pneumonia is associated with the ventilator that can cause an increased mortality risk that it is also related to the degree of the spread and duration of the inflammatory response of the host $[39,40]$.

In this study, the HIS group patients had a higher incidence of mechanical ventilation $(>24 \mathrm{~h})$. It has been also demonstrated that the grade of postoperative inflammation after cardiopulmonary bypass, measured through CRP and migration inhibitory factor (MIF), is strongly connected with degree of pulmonary dysfunction. The MIF levels measured six hours after CPB were inversely related to the postoperative $\mathrm{PaO}_{2} / \mathrm{FiO}_{2}$ ratio and were directly related to the duration of mechanical ventilation [41].

The original finding of this study was that the patients with a high preoperative inflammatory status (HIS) during a 48-month follow-up, had significantly lower survival compared to the patients with a low preoperative inflammatory status (LIS). Moreover, a high inflammatory status and LVEF were independent risk factors for survival. Similar trends were demonstrated in the subgroups of the patients who had undergone CABG and cardiac surgery other than CABG.

The CRP power to predict the adverse cardiac events has been better defined. A large prospective long-term study based on 27,939 healthy women showed that healthy patients with CRP $>0.41 \mathrm{mg} / \mathrm{dL}$ (higher quintile) have significantly lower event-free survival from cardiovascular events in comparison with the patients with CRP $<0.04$ (lower quintile) [42]. A sub-analysis on the same population evidenced the strong prognostic value of very high levels of CRP ( $>2 \mathrm{mg} / \mathrm{dL})$ on the incidence of cardiovascular events (adjusted RR 3.1) [43]. Several prospective studies evidenced that high pre-procedural levels of CRP and FBG significantly affect the long-term survival, freedom from major cardiac events and restenosis rates after PCI [44-47]. In the patients with coronary artery disease, the individual's reactivity to inflammatory stimuli plays an important pathophysiologic role in the progression of atherosclerotic plaques. The presence of a high-grade inflammatory status before CABG could be considered a marker of activity of atherosclerotic disease which can affect the long-term outcome.

Unfortunately, the mechanisms by which CRP and fibrinogen affect the long-term outcomes in the patients who have undergone cardiac surgery different than CABG remain less clear and hypothetical. Krasuski and co-workers evidenced the prognostic value of CRP after percutaneous balloon mitral valve commissurotomy [12]. Moreover, it has been clarified that the patients with either ischemic and non-ischemic heart failure have a chronic activation of the inflammatory network $[13,14]$ and other reports have evidenced that high CRP plasma levels were independent risk factors for hospitalization in the patients with heart failure and were associated with death during the 18-months follow-up $[15,16]$.

\section{Conclusions}

This study highlighted the presence of an association between a preoperative inflammatory status, defined by CPR and fibrinogen, both above the median values (CRP $\geq 0.39 \mathrm{mg} / \mathrm{dL}$ and FBG $\geq$ $366 \mathrm{mg} / \mathrm{dL}$ ), and the occurrence of postoperative infections, particularly regarding the sternal wound. Moreover, a trend toward statistical significance was found for hospital mortality. This finding is supported by the literature [42-52].

The patients receiving the operation with an activated inflammatory system showed an increased inflammatory reaction to cardiac surgery. In the mid-term, the patients with preoperative highly activated inflammatory status had a poor prognosis despite surgical correction of their cardiac disease. This finding seemed to be confirmed either in patients who had undergone CABG and in patients who had undergone cardiac surgery other than CABG. The relationship between the inflammatory status, activity of atherosclerotic processes and left ventricular dysfunction could explain these results. On the other hand, the preoperative inflammatory state is associated with many other events (left ventricular dysfunction, hypertension, the need for other surgical procedures etc.), which can potentially increase the risk for postoperative infection and decrease mid-term survival. Moreover, the co-existing systemic conditions, (i.e.; cancers, recent surgery, diabetes, etc.) can often worsen the outcome of cardiac surgery, 
especially if they are associated with chronic inflammation mostly related to periodontitis or dental decays [53-59]. This is well known from the mid-1950s, so prophylactic dental hygiene is actually prescribed to patients that must have cardiac surgery [60-62]. Then, a correct management of the patients that must have cardiac surgery is mandatory and must include traditional therapies [63-68] and, prospectively, innovative tools and procedures [69-72]. If sepsis arises in the patients who are candidates for cardiac surgery, or have undergone a rapid and correct diagnosis, this should be done from the time of admission to the Emergency Departments, in order to reduce the risk of death [73-75].

The limits of the study are the lack of a prospective design, the limited number of patients for each subset of diseases and the absence of data regarding the statins assumption during the follow-up. Another limit is that post-operative factors as a long duration of stay in the intensive care unit, a higher incidence of mechanical ventilation or post-operative dialysis, etc. may affect the inflammatory status of the patient and could play a role, influencing the outcome.

Future trials are needed in order to ascertain a mid-term protective role of anti-inflammatory agents in the patients who have undergone cardiac surgery with an elevated inflammatory status.

Author Contributions: For research articles with several authors, a short paragraph specifying their individual contributions must be provided. The following statements should be used "conceptualization, D.D.A. and G.C.; methodology, D.P.; validation, C.B.; investigation, all the authors equally; resources, D.D.A.; data curation, C.R., F.M. and F.C.; writing—original draft preparation, D.D.A., T.Q. and G.C.; writing-review and editing, D.D.A., A.C. and G.C.; funding acquisition, I.A.C."

Funding: This research received no external funding.

Conflicts of Interest: The authors declare no conflicts of interest.

\section{References}

1. Pearson, T.A.; Mensah, G.A.; Alexander, R.W.; Anderson, J.L.; 3rd Cannon, R.O.; Criqui, M.; Fadl, Y.Y.; Fortmann, S.P.; Hong, Y.; Myers, G.L.; et al. Markers of Inflammation and Cardiovascular Disease. Application to Clinical and Public Health Practice. A Statement for Healthcare Professionals from the Centers for Disease Control and Prevention and the American Heart Association. Circulation 2003, 28, 499-511. [CrossRef] [PubMed]

2. Zebrack, J.S.; Anderson, J.L.; Maycock, C.A.; Horne, B.D.; Bair, T.L.; Muhlestein, J.B. Intermountain Heart Collaborative (IHC) Study Group. Usefulness of high sensitivity C-reactive protein in predicting long-term risk of death or acute myocardial infarction in patients with unstable or stable angina pectoris or acute myocardial infarction. Am. J. Cardiol. 2002, 89, 145-149. [CrossRef]

3. Bickel, C.; Rupprecht, H.J.; Blankenberg, S.; Espiniola-Klein, C.; Schlitt, A.; Rippin, G.; Hafner, G.; Treude, R.; Othman, H.; Hofmann, K.P.; et al. Relation of markers of inflammation (C-reactive protein, fibrinogen, von Willebrand factor, and leukocyte count) and statin therapy to long-term mortality in patients with angiographically proven coronary artery disease. Am. J. Cardiol. 2002, 89, 901-908. [CrossRef]

4. Yip, H.K.; Wu, C.J.; Chang, H.W.; Yang, C.H.; Yeh, K.H.; Chua, S.; Fu, M. Levels and values of serum high-sensitivity C-reactive protein within 6 hours after the onset of acute myocardial infarction. Chest 2004, 126, 1417-1422. [CrossRef] [PubMed]

5. Chew, D.P.; Bhatt, D.L.; Robbins, M.A.; Penn, M.S.; Schneider, J.P.; Lauer, M.S.; Topol, E.J.; Ellis, S.G. Incremental prognostic value of elevated baseline C-reactive protein among established markers of risk in percutaneous coronary intervention. Circulation 2001, 104, 992-997. [CrossRef] [PubMed]

6. Montalescot, G.; Ankri, A.; Vicaut, E.; Drobinski, G.; Grosgogeat, Y.; Thomas, D. Fibrinogen after coronary angioplasty. Circulation 1995, 92, 31-38. [CrossRef] [PubMed]

7. Ferlan, G.; Berthet-Bondet, M.; De Pasquale, C.; D'Agostino, D.; Deveze, J.L.; Bex, J.P. Percutaneous angioplasty in the treatment of early vein graft stenosis in patients with coronary artery bypass grafts: Observations in 5 cases treated successfully. Cuore 1990, 7, 335-340.

8. Walter, D.H.; Fichtlscherer, S.; Britten, M.B.; Rosin, P.; Auch-Schwelk, W.; Schächinger, V.; Zeiher, A.M. Statin therapy, inflammation and recurrent coronary events in patients following coronary stent implantation. J. Am. Coll. Cardiol.. 2001, 38, 2006-2012. [CrossRef] 
9. Otto, C.M.; Kuusisto, J.; Reichenback, D.D.; Gown, A.M.; O’Brien, K.D. Characterization of the early lesion of "degenerative" valvular aortic stenosis. Histological and immunohistochemical studies. Circulation 1994, 90, 844-853. [CrossRef]

10. Gerber, I.L.; Stewart, R.A.; Hammett, C.J.; Legget, M.E.; Oxenham, H.; West, T.M.; French, J.K.; White, H.D. Effect of aortic valve replacement on $\mathrm{C}$ reactive Protein in Nonrheumatic Aortic Stenosis. Am. J. Cardiol. 2003, 92, 1129-1132. [CrossRef]

11. Galante, A.; Pietroiusti, A.; Vellini, M.; Piccolo, P.; Possati, G.; De Bonis, M.; Grillo, R.L.; Fontana, C.; Favalli, C. C-reactive protein is increased in patients with degenerative aortic valvular stenosis. J. Am. Coll. Cardiol. 2001, 38, 1078-1082. [CrossRef]

12. Samsonov, M.; Lopatin, J.; Tiltz, G.P. The activated immune system and the renin-angiotensin-aldosterone system in congestive heart failure. J. Intern. Med. 1998, 243, 93-98. [CrossRef] [PubMed]

13. MacGowan, G.A.; Mann, D.L.; Kormos, R.L.; Feldman, A.M.; Murali, S. Circulating interleukin-6 in severe heart failure. Eur. Heart J. 1998, 19, 990-1003. [CrossRef]

14. Krasuski, R.A.; Bush, A.; Kay, J.E.; Jr Mayes, C.E.; Wang, A.; Fleming, J.; Pierce, C.; Kisslo, K.B.; Harrison, J.K.; Bashore, T.M. C-reactive protein elevation independently influences the procedural success of percutaneous balloon mitral valve commissurotomy. Am. Heart J. 2003, 146, 1099-1104. [CrossRef]

15. Werdan, K. The activated immune system in congestive heart failure. From dropsy to the cytokine paradigm. J. Intern. Med. 1998, 243, 87-92.

16. Alonso-Martinez, J.L.; Llorente-Diez, B.; Echegaray-Angara, M.; Olaz-Preciado, F.; Urbieta-Echezarreta, M.; Gonzalez-Arencibia, C. C-reactive protein as predictor of improvement and readmission in heart failure. Eur. J. Heart Fail. 2002, 4, 331-336. [CrossRef]

17. Biancari, F.; Lahtinen, J.; Lepojarvi, S.; Rainio, P.; Salmela, E.; Pokela, R.; Lepojärvi, M.; Satta, J.; Juvonen, T.S. Preoperative C-reactive protein and outcome after coronary artery bypass. Ann. Thorac. Surg. 2003, 76, 2007-2012. [CrossRef]

18. Boeken, U.; Feindt, P.; Zimmermann, N.; Kalweiy, G.; Petzold, T.; Gams, E. Increased preoperative C-reactive protein (CRP)-values without signs of an infection and complicated course after cardiopulmonary bypass (CPB) - operations. Eur. J. Cardio-thorac. Surg. 1998, 13, 541-545. [CrossRef]

19. Fransen, E.J.; Maessen, J.G.; Elenbaas, T.W.; van Aarnhem, E.E.; Dieijen-Visser, M.P. Increased preoperative C-Reactive protein plasma levels as risk factor for post-operative infections. Ann. Thorac. Surg. 1999, 67, 134-138. [CrossRef]

20. Mervyn, S.; Deutschman, C.S.; Seymour, C.W.; Shankar-Hari, M.; Annane, D.; Bauer, M.; Bellomo, R.; Gordon, R.B.; Chiche, J.D.; Coopersmith, C.M.; et al. The Third International Consensus Definitions for Sepsis and Septic Shock (Sepsis-3). JAMA 2016, 315, 801-810.

21. Osmand, A.P.; Friedenson, B.; Gewurz, H.; Painter, R.H.; Hofmann, T.; Shelton, E. Characterization of C-reactive protein and the complement subcomplement $\mathrm{C} 1 \mathrm{t}$ as homologous proteins displaying cyclic pentameric symmetry (pentraxins). Proc. Natl. Acad. Sci. USA 1977, 74, 739-743. [CrossRef] [PubMed]

22. Gaudino, M.; Nasso, G.; Andreotti, F.; Minniti, G.; Iacoviello, L.; Donati, M.; Schiavello, R.; Possati, G. Preoperative C-reactive protein level and outcome following cardiac surgery. Eur. J. Cardio-thorac. Surg. 2002, 22, 521-526. [CrossRef]

23. Paparella, D.; Yau, T.M.; Young, E. Cardiopulmonary bypass induced inflammation: pathophysiology and treatment. An update. Eur. J. Cardiothorac. Surg. 2002, 21, 232-244. [CrossRef]

24. Royster, R.L.; Grosshans, D.W.; Kon, N.D. A multimodal approach to address the inflammation of cardiopulmonary bypass? J. Cardiothorac Vasc. Anesth. 2011, 25, e35. [CrossRef] [PubMed]

25. Gnoni, A.; Ballini, A.; Trentadue, R.; Taurino, F.; Santacroce, L.; Ferrara, P.; Massaro, F.; Brienza, N.; Massari, A.M.; Sardaro, N.; et al. Induction of mitochondrial dysfunction in patients under cardiopulmonary by-pass: preliminary results. Eur. Rev. Med. Pharmacol. Sci. 2019, 23, 8115-8123.

26. O'Neil, M.P.; Fleming, J.C.; Badhwar, A.; Guo, L.R. Pulsatile versus nonpulsatile flow during cardiopulmonary bypass: microcirculatory and systemic effects. Ann. Thorac. Surg. 2012, 94, 2046-2053. [CrossRef]

27. Dieleman, J.M. Corticosteroids for the inflammatory response to cardiopulmonary bypass: an update. Curr. Pharm. Des. 2013, 19, 3979-3991. [CrossRef]

28. Landis, R.C.; Brown, J.R.; Fitzgerald, D.; Likosky, D.S.; Shore-Lesserson, L.; Baker, R.A.; Hammon, J.W. Attenuating the systemic inflammatory response to adult cardiopulmonary bypass: A critical review of the Evidence Base. J. Extra Corpor. Technol. 2014, 46, 197-211. 
29. Takeuchi, K.; Cao-Danh, H.; Friehs, I.; Glynn, P.; D’Agostino, D.; Simplaceanu, E.; McGowan, F.X.; del Nido, P.J. Administration of fructose 1,6-diphosphate during early reperfusion significantly improves recovery of contractile function in the post ischemic heart. J. Thorac. Cardiovasc Surg. 1998, 116, 335-343. [CrossRef]

30. Petrosillo, G.; Di Venosa, N.; Ruggiero, F.M.; Pistolese, M.; D’Agostino, D.; Tiravanti, E.; Fiore, T.; Paradies, G. Mitochondrial dysfunction associated with cardiac ischemia/reperfusion can be attenuated by oxygen tension control. Role of oxygen-free radicals and cardiolipin. Biochim. Biophys. Acta-Bioenergetics 2005, 1710, 78-86. [CrossRef]

31. Giordano, P.; Scrascia, G.; D'Agostino, D.; Mastro, F.; Rotunno, C.; Conte, M.; Rociola, R.; Paparella, D. Myocardial damage following cardiac surgery: Comparison between single-dose Celsior cardioplegic solution and cold blood multi-dose cardioplegia. Perfusion 2013, 28, 496-503. [CrossRef] [PubMed]

32. Colantuono, G.; Tiravanti, E.A.; Di Venosa, N.; Cazzato, A.; Rastaldo, R.; Cagiano, R.; D'Agostino, D.; Federici, A.; Fiore, T. Hyperoxia confers myocardial protection in mechanically ventilated rats through the generation of free radicals and opening of mitochondrial ATP-sensitive potassium channels. Clin. Exp. Pharmacol. Physiol. 2008, 35, 64-71. [CrossRef] [PubMed]

33. Di Venosa, N.; Masciopinto, F.; Romito, F.M.; Altea Tiravanti, E.; Schena, S.; Fasanella, E.; D'Agostino, D.; Pappagallo, L.; Federici, A.; Fiore, T. Hypoxic reperfusion limits functional impairment following cardioplegic arrest in isolated rat heart. Minerva Anestesiologica 2001, 67, 509-517. [PubMed]

34. Bortone, A.S.; D'Agostino, D.; Schena, S.; Rubini, G.; Viecca, M.; Sardaro, V.; Tucci, A.; De Luca Tupputi Schinosa, L. Instrumental validation of percutaneous transmyocardial revascularization: Follow-up at one year. Ann. Thoracic. Surg. 2000, 70, 1115-1118. [CrossRef]

35. Bortone, A.S.; D’Agostino, D.; Schena, S.; Rubini, G.; Brindicci, P.; Sardaro, V.; D'Addabbo, A.; De Luca Tupputi Schinosa, L. Inflammatory response and angiogenesis after percutaneous transmyocardial laser revascularization. Ann. Thoracic. Surg. 2000, 70, 1134-1138. [CrossRef]

36. Serviddio, G.; Di Venosa, N.; Federici, A.; D'Agostino, D.; Rollo, T.; Prigigallo, F.; Altomare, E.; Fiore, T.; Vendemiale, G. Brief hypoxia before normoxic reperfusion (postconditioning) protects the heart against ischemia-reperfusion injury by preventing mitochondria peroxyde production and glutathione depletion. FASEB J. 2005, 19, 354-361. [CrossRef]

37. Denis, M.; Campbell, D.; Gregg, E.O. Interleukin-2 and granulocyte-macrophage colony-stimulating factor stimulate growth of a virulent strain of Escherichia Coli. Infect. Immunol. 1991, 59, 1853-1856.

38. Raffaella, T.; Fiore, F.; Fabrizia, M.; Francesco, P.; Arcangela, I.; Salvatore, S.; Luigi, S.; Nicola, B. Induction of mitochondrial dysfunction and oxidative stress in human fibroblast cultures exposed to serum from septic patients. Life Sci. 2012, 91, 237-243. [CrossRef]

39. Meduri, G.U.; Kanagat, S.; Stefan, J.; Tolley, E.; Schaberg, S. Cytokines IL-1beta, IL-6 and TNF-alpha enhance in vitro growth of bacteria. Am. J. Respir. Crit. Care Med. 1999, 160, 961-967. [CrossRef]

40. Meduri, G.U. Clinical review: A paradigm shift: The bidirectional effect of inflammation on bacterial growth. Clinical implications for patients with acute respiratory distress syndrome. Critical Care 2002, 6, 24-29. [CrossRef]

41. Furtado de Mendonca-Filho, H.T.; Gomes, R.V.; Campos, L.A.; Tura, B.; Nunes, E.M.; Gomes, R.; Bozza, F.; Bozza, P.T.; Castro-Faria-Neto, H.C. Circulating levels of macrophage migration inhibitory factor are associated with mild pulmonary dysfunction after cardiopulmonary bypass. Shock 2004, 22, 533-537. [CrossRef] [PubMed]

42. Ridker, P.M.; Rifai, N.; Rose, L.; Buring, J.E.; Cook, N.R. Comparison of C-reactive protein and low density lipoprotein cholesterol levels in the prediction of first cardiovascular event. N. Engl. J. Med. 2002, 347, 1557-1565. [CrossRef] [PubMed]

43. Ridker, P.M.; Cook, N.R. Clinical Usefulness of Very High and Very Low levels of C-reactive protein Across the Full Range of Framingham Risk Scores. Circulation 2004, 109, 1955-1959. [CrossRef] [PubMed]

44. Dibra, A.; Mehilli, J.; Braun, S.; Hadamitzky, M.; Baum, H.; Dirschinger, J.; Schühlen, H.; Schömig, A.; Kastrati, A. Association between C-Reactive Protein Levels and Subsequent Cardiac Events among Patients with Stable Angina Treated with Coronary Artery Stenting. Am. J. Med. 2003, 114, 715-722. [CrossRef]

45. Walter, D.H.; Fichtlscherer, S.; Sellwig Auch-Schwelk, W.; Schächinger, V.; Zeiher, A.M. Preprocedural C-Reactive Protein Levels and Cardiovascular Events After Coronary Stent Implantation. J. Am. Coll. Cardiol. 2001, 37, 839-846. [CrossRef] 
46. Rahel, B.M.; Visseren, F.L.; Suttorp, M.J.; Plokker, T.H.; Kelder, J.C.; de Jongh, B.M.; Bouter, K.P.; Diepersloot, R.J. Preprocedural serum levels of acute-phase reactants and prognosis after percutaneous coronary intervention. Cardiovasc Res. 2003, 60, 136-140. [CrossRef]

47. Otsuka, M.; Hayashi, Y.; Ueda, H.; Imazu, M.; Kohno, N. Predictive value of preprocedural fibrinogen concerning coronary stenting. Atherosclerosis 2002, 164, 371-378. [CrossRef]

48. D'Agostino, D.; Bottalico, L.; Santacroce, L. Infective endocarditis: What is changed in epidemiology and prophylaxis. Acta Medica Medit. 2012, 28, 311-319.

49. D'Agostino, D. Infective endocarditis today. F1000 Res. 2017, 6, 2188. [CrossRef]

50. D'Agostino, D.; Man, A.; Santacroce, L. Current trends in cardiac surgery: Clinical experience in the treatment of mediastinitis with sternal wound infection through negative pressure therapy. Acta Medica Medit. 2016, 32, 1905-1910.

51. D'agostino, D.; Lacatena, C.; Santacroce, L. Postoperative mediastinitis in cardiac surgery-pathophysiology, risk factors and prevention. Acta Medica Medit. 2015, 31, 1311-1318.

52. D'Agostino, D.; Losacco, T.; Santacroce, L. Clinical management of the infective endocarditis today. Acta Medica Medit. 2012, 28, 321-329.

53. Prejbeanu, R.; Vermesan, H.; Dragulescu, S.I.; Vermesan, D.; Motoc, A.; Sabatini, R.; Santacroce, L.; Cagiano, R. Thromboembolic risk after knee endoprosthesis. Eur. Rev. Med. Pharmacol. Sci. 2007, 11, 297-300. [PubMed]

54. Ballini, A.; Cantore, S.; Farronato, D.; Cirulli, N.; Inchingolo, F.; Papa, F.; Malcangi, G.; Inchingolo, A.D.; Dipalma, G.; Sardaro, N.; et al. Periodontal disease and bone pathogenesis: the crosstalk between cytokines and porphyromonas gingivalis. J. Biol. Regul. Homeost Agents. 2015, 29, 273-281. [PubMed]

55. Vermesan, D.; Vermesan, H.; Dragulescu, S.I.; Bera, I.; Di Giovanni, A.; Sabatini, R.; Santacroce, L.; Bottalico, L.; Flace, P.; Cagiano, R. Secondary pathologic fractures in osteosarcoma: prognosis and evolution. Eur. Rev. Med. Pharmacol. Sci. 2009, 13, 71-76. [PubMed]

56. Santacroce, L.; Cagiano, R.; Del Prete, R.; Bottalico, L.; Sabatini, R.; Carlaio, R.G.; Prejbeanu, R.; Vermesan, H.; Dragulescu, S.I.; Vermesan, D.; et al. Helicobacter pylori infection and gastric MALTomas: an up-to-date and therapy highlight. Clin. Ter. 2008, 159, 457-462.

57. Santacroce, L.; Carlaio, R.G.; Bottalico, L. Does it make sense that diabetes is reciprocally associated with periodontal disease? Endocr. Metab. Immune Disord. Drug Targets 2010, 10, 57-70. [CrossRef]

58. Giudice, G.; Cutrignelli, D.A.; Sportelli, P.; Limongelli, L.; Tempesta, A.; Gioia, G.D.; Santacroce, L.; Maiorano, E.; Favia, G. Rhinocerebral Mucormycosis with Orosinusal Involvement: Diagnostic and Surgical Treatment Guidelines. Endocr. Metab. Immune Disord. Drug Targets 2016, 16, 264-269. [CrossRef]

59. Ballini, A.; Cantore, S.; Dedola, A.; Santacroce, L.; Laino, L.; Cicciù, M.; Mastrangelo, F. IL-1 haplotype analysis in periodontal disease. J. Biol. Regul. Homeost Agents 2018, 32, 433-437.

60. Santacroce, L.; Cagiano, R.; Carlaio, R.G.; Del Prete, R.; Bottalico, L. Dentistry oral hygiene and endocarditis. Pathophysiology and prophylactic therapy. Recenti Progr. Med. 2008, 99, 516-521.

61. Santacroce, L.; Bottalico, L.; Mangini, F. Dental hygiene procedure in a patient with Giardia lamblia infection. Int. J. Dent. Hyg. 2007, 5, 187-189. [CrossRef] [PubMed]

62. Bottalico, L.; Valenzano, A.; Leone, D.; Mangini, F.; Santacroce, L. The incidence of dental caries during childhood. A clinical and epidemiologic study in Matera (Southern Italy). Clin. Ter. 2007, 158, 409-419. [PubMed]

63. Campanella, V.; Syed, J.; Santacroce, L.; Saini, R.; Ballini, A.; Inchingolo, F. Oral probiotics influence oral and respiratory tract infections in pediatric population: a randomized double-blinded placebo-controlled pilot study. Eur. Rev. Med. Pharmacol Sci. 2018, 22, 8034-8041. [PubMed]

64. Santacroce, L.; Charitos, I.A.; Bottalico, L. A successful history: probiotics and their potential as antimicrobials. Expert Rev. Anti Infect. Ther. 2019, 17, 635-645. [CrossRef]

65. Ballini, A.; Santacroce, L.; Cantore, S.; Bottalico, L.; Dipalma, G.; Topi, S.; Saini, R.; De Vito, D.; Inchingolo, F. Probiotics Efficacy on Oxidative Stress Values in Inflammatory Bowel Disease: A Randomized Double-Blinded Placebo-Controlled Pilot Study. Endocr. Metab. Immune Disord. Drug Targets 2019, 19, 373-381. [CrossRef]

66. Ballini, A.; Santacroce, L.; Cantore, S.; Bottalico, L.; Dipalma, G.; Vito, D.; Saini, R.; Inchingolo, F. Probiotics Improve Urogenital Health in Women. Open Access Maced. J. Med. Sci. 2018, 6, 1845-1850. [CrossRef]

67. Man, A.; Santacroce, L.; Iacob, R.; Mare, A.; Man, L. Antimicrobial Activity of Six Essential Oils Against a Group of Human Pathogens: A Comparative Study. Pathogens 2019, 8, 15. [CrossRef] 
68. Inchingolo, F.; Dipalma, G.; Cirulli, N.; Cantore, S.; Saini, R.S.; Altini, V.; Santacroce, L.; Ballini, A.; Saini, R. Microbiological results of improvement in periodontal condition by administration of oral probiotics. J. Biol. Regul Homeost Agents. 2018, 32, 1323-1328.

69. Santacroce, L.; D'Agostino, D.; Charitos, I.A.; Bottalico, L.; Ballini, A. A short review about electrophysiology and bioimpedance: History and perspectives. Indian J. Public Health Res. Develop. 2018, 9, 577-591. [CrossRef]

70. Santacroce, L.; Charitos, I.A.; Topi, S.; Bottalico, L. The Alcmaeon's School of Croton: Philosophy and Science. Open Access Maced. J. Med. Sci. 2019, 28, 500-503. [CrossRef]

71. Santacroce, L.; Bottalico, L.; Charitos, I.A. Greek Medicine Practice at Ancient Rome: The Physician Molecularist Asclepiades. Medicines (Basel) 2017, 4, 92. [CrossRef] [PubMed]

72. Cantore, S.; Crincoli, V.; Boccaccio, A.; Uva, A.E.; Fiorentino, M.; Monno, G.; Bollero, P.; Derla, C.; Fabiano, F.; Ballini, A.; et al. Recent Advances in Endocrine, Metabolic and Immune Disorders: Mesenchymal Stem Cells (MSCs) and Engineered Scaffolds. Endocr. Metab. Immune Disord. Drug Targets 2018, 18, 466-469. [CrossRef] [PubMed]

73. Di Serio, F.; Lovero, R.; D'Agostino, D.; Nisi, L.; Miragliotta, G.; Contino, R.; Man, A.; Ciccone, M.M.; Santacroce, L. Evaluation of procalcitonin, Vitamin D and C-reactive protein levels in septic patients with positive emocoltures. Our preliminary experience. Acta Medica Medit. 2016, 32, 1911-1914.

74. Charitos, I.A.; Topi, S.; Castellaneta, F.; D'Agostino, D. Current issues and perspectives in patients with possible sepsis at Emergency Departments. Antibiotics (Basel) 2019, 8, 56. [CrossRef] [PubMed]

75. Del Prete, R.; Ronga, L.; Addati, G.; Magrone, R.; Abbasciano, A.; Carlo, D.D.; Santacroce, L. A Retrospective Study about the Impact of Switching from Nested PCR to Multiplex Real-Time PCR on the Distribution of the Human Papillomavirus (HPV) Genotypes. Medicina (Kaunas) 2019, 55, 418. [CrossRef] [PubMed]

(C) 2019 by the authors. Licensee MDPI, Basel, Switzerland. This article is an open access article distributed under the terms and conditions of the Creative Commons Attribution (CC BY) license (http://creativecommons.org/licenses/by/4.0/). 